\title{
Allyl isothiocyanate induced stress response in Caenorhabditis elegans
}

\author{
AkalRachna K Saini ${ }^{1,2}$, Robert T Tyler ${ }^{1}$, Youn Young Shim ${ }^{3}$ and Martin JT Reaney ${ }^{3^{*}}$
}

\begin{abstract}
Background: Allyl isothiocyanate (AITC) from mustard is cytotoxic; however the mechanism of its toxicity is unknown. We examined the effects of AITC on heat shock protein (HSP) 70 expression in Caenorhabditis elegans. We also examined factors affecting the production of AITC from its precursor, sinigrin, a glucosinolate, in ground Brassica juncea cv. Vulcan seed as mustard has some potential as a biopesticide.

Findings: An assay to determine the concentration of AITC in ground mustard seed was improved to allow the measurement of AITC release in the first minutes after exposure of ground mustard seed to water. Using this assay, we determined that temperatures above $67^{\circ} \mathrm{C}$ decreased sinigrin conversion to AITC in hydrated ground B. juncea seed. A pH near 6.0 was found to be necessary for AITC release. RT-qPCR revealed no significant change in HSP70A mRNA expression at low concentrations of AITC $(<0.1 \mu \mathrm{M})$. However, treatment with higher concentrations $(>1.0$ $\mu \mathrm{M})$ resulted in a four- to five-fold increase in expression. A HSP70 ELISA showed that AITC toxicity in C. elegans was ameliorated by the presence of ground seed from low sinigrin B. juncea cv. Arrid.
\end{abstract}

Conclusions: - AITC induced toxicity in C. elegans, as measured by HSP70 expression.

- Conditions required for the conversion of sinigrin to AITC in ground B. juncea seed were determined.

- The use of $C$. elegans as a bioassay to test AITC or mustard biopesticide efficacy is discussed.

Keywords: Brassica, myrosinase, glucosinolate, HSP70, toxicity, ELISA

\section{Background}

Plant seeds have evolved a broad spectrum of natural defense mechanisms, such as physical and chemical barriers. Mustard species mitigate a wide range of biotic challenges using the glucosinolate-myrosinase system, also referred to as 'The Mustard Bomb' [1]. Glucosinolates (glucoraphanin, glucoerucin, gluconasturtiin, sinigrin, glucotropaeolin, glucoraphenin, glucoraphasatin, glucomoringin and glucobrassicin) are hydrolysed by the enzyme myrosinase (thioglucosidase) to produce an aglycone, which undergoes spontaneous non-enzymatic rearrangement to produce organic isothiocyanates, thiocyanates, nitriles, epithionitriles, oxazolidinethiones and organic cyanates [2-4].

Many glucosinolate products, including allyl isothiocyanate (AITC), are of interest because of their broad

\footnotetext{
* Correspondence: martin.reaney@usask.ca

${ }^{3} 51$ Campus Drive, Department of Plant Sciences, University of

Saskatchewan, Saskatoon, Saskatchewan S7N 5A8, Canada Full list of author information is available at the end of the article
}

spectra of biological activities. For example, the toxicity of Indian mustard and AITC were demonstrated on masked chafer Beetle larvae [5]. The biopesticidal [6,7], fungicidal $[6,8]$, antibiotic $[9,10]$ and nematocidal $[11,12]$ properties of AITC also have been studied.

Caenorhabditis elegans has been used as a model system to study stress responses. The stress response in $C$. elegans and most other organisms is characterized by the rapid expression of heat shock proteins (HSPs). There is extensive evidence in the literature that HSPs play an important role in the tolerance of an organism to a variety of biotic and abiotic stresses that are not immediately lethal, by maintaining cell function and survival during stress or by facilitating recovery after removal of a stressor [13,14].

During cellular stress, members of the highly conserved and ubiquitous $70 \mathrm{kDa}$ heat shock protein (HSP70) family are involved in preventing protein aggregation and refolding of denatured proteins [14]. HSP70 is involved in regulating the heat shock response and
C Biomed Central 
other stresses through mitogen-activated protein kinase (MAPK) signaling [15]. Heschl and Baillie [16] characterized the HSP70 multigene family in C. elegans.

Interest in using Brassica material as a biopesticide requires a robust assay to determine AITC production and a bioassay to determine sample effectiveness. In the present study, we developed a method for measuring AITC in ground mustard shortly after the addition of water. In addition, we report various factors affecting AITC release in vitro. The effect of AITC and ground mustard on $C$. elegans was determined by measuring the transcription and translation of nematode HSP70 as an indicator of stress.

\section{Materials and methods}

Brassica juncea cv. Arrid was obtained from Derek Potts of Viterra, Saskatoon, SK. B. juncea cv. Vulcan and Sinapis alba seed were obtained from Kevin Falk, Agriculture and Agri-Food Canada, Saskatoon Research Centre, Saskatoon, SK. Seed was produced on plots near Saskatoon in 2006.

\section{Modifying the AITC ground seed assay}

The method to extract AITC from ground seed and determine its concentration is essentially that of Raquet [17]. Glucosinolates in ground seed are converted to isothiocyanates by continuously stirring $5 \mathrm{~g}$ of seed in 100 $\mathrm{mL}$ of water at $37^{\circ} \mathrm{C}$ for $2 \mathrm{~h}$. AITC in ground seed is then recovered by adding $20 \mathrm{~mL}$ of $95 \%$ ethanol and a few boiling chips. Sixty millilitres of the distillate was collected in a flask containing $10 \mathrm{~mL}$ of $33.5 \%$ ammonium hydroxide solution and $20 \mathrm{~mL}$ of $0.1 \mathrm{~N}$ silver nitrate was added. The final volume was adjusted to 100 $\mathrm{mL}$ with distilled water and incubated overnight in the dark at room temperature. The resulting black precipitate was removed by filtration with Whatman grade No. 4 filter paper (GE Health Care, Piscataway, NJ) and two titrations were performed, each using $50 \mathrm{~mL}$ of this filtrate. The filtrate $(50 \mathrm{~mL})$ was acidified with $5 \mathrm{~mL}$ of concentrated nitric acid (analytical grade, Sigma-Aldrich, Oakville, ON, Canada) and was titrated with $0.1 \mathrm{~N}$ ammonium thiocyanate (analytical grade, Sigma-Aldrich) after adding $5 \mathrm{~mL}$ of $8 \% \mathrm{FeNH}_{4}\left(\mathrm{SO}_{4}\right)_{2} \cdot 12 \mathrm{H}_{2} \mathrm{O}$ indicator (Sigma-Aldrich). Percent volatile oil was calculated by:

$$
\text { Volatile oil }(\%)=\frac{\left[(\mathrm{mL} \times \mathrm{N}) \mathrm{AgNO}_{3}-2(\mathrm{~mL} \times \mathrm{N}) \mathrm{NH}_{4} \mathrm{SCN}\right] \times 0.04958 \times 100}{\text { Weight of sample }(\mathrm{g})}
$$

We examined the effects of varying the incubation time, solvent and temperature on AITC release by ground $B$. juncea seed. The effects of various durations (0-5 min at $30 \mathrm{~s}$ intervals and 5, 15, 30, 60 and 120 min), temperatures $\left(7\right.$ to $97^{\circ} \mathrm{C}$ ) and solvents (water, $0.02 \mathrm{~N}$ sodium hydroxide, $0.02 \mathrm{~N}$ hydrochloric acid, $0.02 \mathrm{~N}$ acetic acid) on percent volatile oil released were examined. Four replicates of each treatment were performed.

\section{C. elegans culture and AITC treatment}

C. elegans N2 strain was grown on $10 \%$ bacteriological agar (Sigma-Aldrich) layered with $1 \mathrm{~mL}$ of autoclaved $1 \%(\mathrm{w} / \mathrm{v})$ Baker's yeast in sterile $10-\mathrm{mm}$ diameter plates. Cultures were incubated in the dark at room temperature and sub-cultured to fresh plates every 15 days.

Two-week-old cultures of C. elegans were treated with 0-10 $\mu \mathrm{M}$ of commercially prepared AITC (SigmaAldrich) and/or 0.0-144.5 $\mu \mathrm{g} / \mathrm{mL}$ B. juncea cv. Arrid ground seed and incubated in the dark at room temperature for $2 \mathrm{~h}$. After treatment and incubation, cultures were centrifuged at $400 \times \mathrm{g}$ for $10 \mathrm{~min}$ at $4^{\circ} \mathrm{C}$ and the pellet was stored at $-80^{\circ} \mathrm{C}$ pending further analysis.

\section{RNA isolation and quantitative RT-PCR analysis}

Total RNA was extracted from C. elegans lysates stored at $-80^{\circ} \mathrm{C}$ using an RNeasy Mini kit (Qiagen Inc., Mississauga, ON, Canada) according to the manufacturer's instructions. The integrity of RNA was confirmed by agarose gel electrophoresis and RNA was quantified using a Nano drop spectrophotometer (Thermo, Fisher Scientific, Ottawa, ON, Canada). Following DNase treatment, the mRNA was reverse transcribed at $42^{\circ} \mathrm{C}$ for 30 min using the QuantiTect Reverse Transcription kit (Qiagen Inc.) as per the manufacturer's instructions. This cDNA was used for quantitative real-time RT-PCR (qRTPCR) analysis for the expression of HSP70A (GenBank Accession No. M18540) using the QuantiFast SYBR Green kit (Qiagen Inc.) as per the manufacturer's instructions. The glyceraldehyde-3-phosphate dehydrogenase gene (GAPDH; GenBank Accession X04818) was used as the reference housekeeping gene. The reactions were performed using the following primer pairs: 5'-ATGAGTAAGCATAACGCTGTT-3' and 5'ACAGTGTTATGTGGGTTCATG-3' for a 200 bp HSP70A fragment and 5'-AACCATGAGAAGTACGAC3' and 5'-CTGTCTTCTGGGTTGCGG-3' for a $212 \mathrm{bp}$ GAPDH fragment. A negative control reaction consisted of all the components of the reaction mixture except cDNA. Real-time PCR analysis was performed using a MX3005P LightCycler (Stratagene, La Jolla, CA, USA) and the following program: initial denaturation at $94^{\circ} \mathrm{C}$ for $5 \mathrm{~min}$; 45 cycles of denaturation at $94^{\circ} \mathrm{C}$ for $15 \mathrm{~s}$; annealing at $57^{\circ} \mathrm{C}$ for $30 \mathrm{~s}$; and elongation at $68^{\circ} \mathrm{C}$ for 60 sec. Relative expression levels were calculated after correction for expression of GAPDH using MxPro software.

\section{Quantification of HSP70 by an enzyme-linked immunosorbant assay (ELISA)}

As HSP70A is a cytoplasmic protein known to be expressed in response to stress or toxicity, studies on 
the effects of AITC on C. elegans focused on expression of this protein. A 52 amino acid residue fragment at the C-terminal end of HSP70A (GenBank accession AAA28078) showed > 98\% identity to the human HSP70 (GenBank accession NP_005337). A goat antibody raised against the human peptide of this peptide fragment was purchased from AbCam (Cambridge, MA, USA).

C. elegans samples stored at $-80^{\circ} \mathrm{C}$ were ground to a fine powder under liquid nitrogen using a sterile mortar and pestle. Ground tissues were incubated in 200 $\mu \mathrm{L}$ of freshly prepared lysis buffer $(50 \mathrm{mM}$ Tris- $\mathrm{HCl}$, pH 7.4; $150 \mathrm{mM} \mathrm{NaCl} ; 1 \% \mathrm{NP}-40 ; 1 \mathrm{mM}$ phenylmethylsulfonyl fluoride; $5 \mu \mathrm{g} / \mathrm{mL}$ antipain; $5 \mu \mathrm{g} / \mathrm{mL}$ aprotinin; $5 \mu \mathrm{g} / \mathrm{mL}$ leupeptin; $7.5 \%$ polyvinylpolypyrrolidone) on ice for $30 \mathrm{~min}$. The lysate was stored at $-80^{\circ} \mathrm{C}$ until further use. Total protein was quantified using the Bradford dye-binding assay (Bio-Rad Laboratories, Hercules, CA, USA) as per the manufacturer's instructions.
Levels of induced HSP70 were measured in protein extracts from AITC-treated worms using a sandwich ELISA kit (Stressgen Biotechnologies, Ann Arbor, MI, USA) as per the manufacturer's instructions. Absorbance at $450 \mathrm{~nm}$ was measured using a NOVOstar microplate reader (BMG Labtech, Durham, NC, USA). The HSP70 concentrations of the samples were quantified by interpolating absorbance readings from the standard curve.

\section{Results}

\section{Effects of temperature and $\mathrm{pH}$ on AITC release}

Modifications were made to the method of Raquet [17], which is used by industry to measure total AITC in ground mustard products. Initially, we examined if myrosinase could be inactivated rapidly so that incubation could be reduced from the two hours specified. High levels of AITC production in ground B. juncea cv. Vulcan seeds suspended in water at $27^{\circ} \mathrm{C}$ were observed after one minute (Figure 1a).

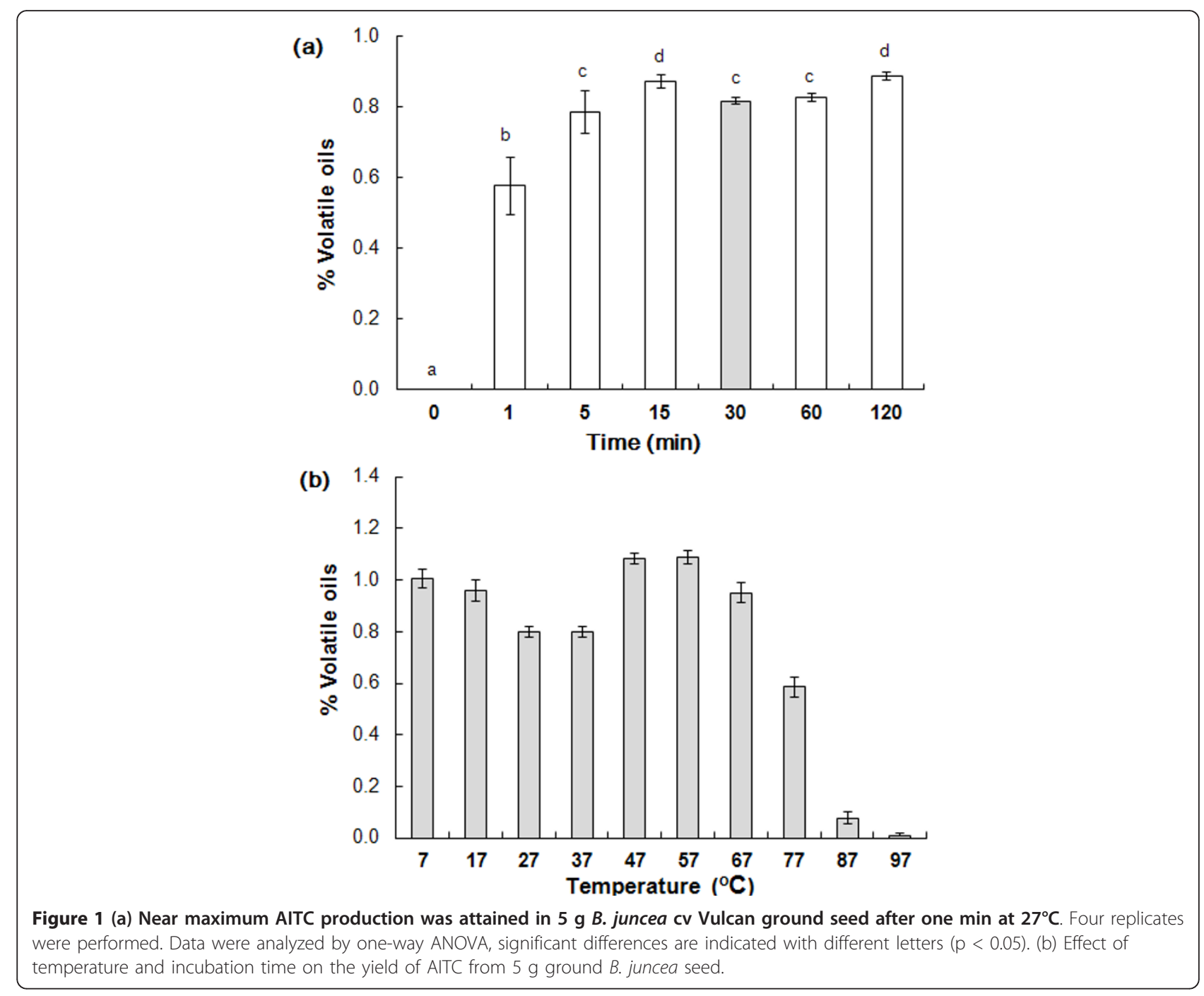


We next determined the effects of temperature and $\mathrm{pH}$ on AITC production in ground B. juncea cv. Vulcan seed. The rate of AITC release decreased at temperatures greater than $67^{\circ} \mathrm{C}$ (Figure $1 \mathrm{~b}$ ). Some AITC was released from the ground seed at $77^{\circ} \mathrm{C}$, but two hours at this temperature did not result in AITC production equivalent to that achieved at lower temperatures. AITC release was almost completely inhibited at temperatures above $87^{\circ} \mathrm{C}$.

AITC concentration was determined after reacting ground seed with $0.02 \mathrm{~N}$ solutions of $\mathrm{NaOH}$, $\mathrm{CH}_{3} \mathrm{COOH}$ and $\mathrm{HCl}$ at $\mathrm{pH} 13.0,3.0$ and 1.5, respectively, and the results were compared with those for the control (water at $\mathrm{pH}$ 6.0). The reactions were conducted at $27^{\circ} \mathrm{C}$ for $5 \mathrm{~min}$. An increase or decrease in $\mathrm{pH}$ resulted in a reduction in enzyme activity as compared to the control (Table 1), indicating that the enzyme had a near-neutral optimum. Some AITC release occurred from ground seed incubated in the presence of $\mathrm{NaOH}$ or $\mathrm{CH}_{3} \mathrm{COOH}$. Returning the $\mathrm{pH}$ to 6.0 in these two reactions resulted in the release of additional AITC (Table 1). Hydrochloric acid irreversibly blocked further AITC release, however. Glucosinolates were not adversely affected by acetic or hydrochloric acid or sodium hydroxide as the addition of $1 \mathrm{~g}$ of ground $S$. alba seed (a source of enzyme, but devoid of substrate, i.e. sinigrin) to the neutralized treatments released AITC, presumably from unreacted sinigrin.

\section{Exposure to AITC induces expression of HSP70A in C. elegans}

Nematodes were visibly injured by treatment with AITC, as was indicated by their movement. Nematodes were actively moving at all concentrations of AITC below 10 $\mu \mathrm{M}$, but higher concentrations appeared to be lethal as their movement stopped.

No significant changes, compared to the control, in the levels of HSP70A transcripts were detected by qRTPCR at concentrations of AITC of $0.1 \mu \mathrm{M}$ or lower. However, C. elegans treated with higher concentrations of AITC (1 to $10 \mu \mathrm{M}$ ) responded with a 4- to 5-fold increase in expression of HSP70A transcripts (Figure 2). These results further confirm that AITC induces stress in C. elegans.
HSP70 protein in C. elegans exposed to different concentrations $(0-20 \mu \mathrm{M})$ of AITC for two hours at room temperature was observed by Western blotting followed by immunodetection with anti-HSP70 monoclonal antibody raised against human peptide (Figure 2). C. elegans treated with AITC at concentrations greater than $1 \mu \mathrm{M}$ showed an increase in HSP70 expression.

\section{Ground mustard seed toxicity is due to AITC}

The above experiments suggest that concentrations of AITC greater than $1 \mu \mathrm{M}$ caused toxicity in C. elegans. However, it is important to know whether other compounds in ground mustard seed, other than AITC, could also contribute to toxicity. We used an ELISA to determine the effect of ground mustard seed on AITCinduced HSP70 expression.

B. juncea cv. Arrid contains greatly reduced levels of sinigrin, the precursor of AITC, and was used to treat C. elegans, with or without additional AITC. The dose was based on AITC levels of $1 \%$ of the total ground seed. Total protein extract from $C$. elegans treated with AITC $(0-10 \mu \mathrm{M})$, B. juncea cv. Arrid (0-144.5 $\mu \mathrm{g})$ or AITC $(0-10 \mu \mathrm{M})+$ B. juncea cv. Arrid (0-144.5 $\mu \mathrm{g})$ for $2 \mathrm{~h}$ was analyzed by ELISA.

As expected, AITC alone resulted in significant increases in the expression of HSP70 protein (Table 2). ELISA was able to detect HSP70 expression at 0.001 $\mu \mathrm{M}$. Only the highest concentration of ground B. juncea cv. Arrid seed $(144.5 \mu \mathrm{g})$ induced the expression of HSP70 proteins. C. elegans treated with both AITC and ground seed showed increased expression of HSP70 proteins, but the levels of induction were lower than those observed with an equivalent concentration of AITC alone.

\section{Discussion}

Condiment mustard has a characteristic flavour, which is contributed by glucosinolate hydrolysis products, AITC in particular. Use of mustard, as a biopesticide is an application based on the toxicity of AITC. Other applications where a broad spectrum of toxicity and volatility are advantageous, e.g. in antimicrobial preparations, could also take advantage of AITC. A convenient assay for AITC production in ground seed and sensitive

Table 1 Effect of $\mathrm{pH}$ on the yield of AITC.

\begin{tabular}{|c|c|c|c|c|}
\hline Alkali/Acid & $\mathrm{pH}$ & $\%$ volatile oil & $\begin{array}{l}\text { Neutralized to } \\
\text { pH } 6.0 \\
\text { (\% volatile oil) }\end{array}$ & $\begin{array}{c}\text { Addition of } 1 \mathrm{~g} \text { powdered } \\
\text { S. alba seed } \\
(\% \text { volatile oil })\end{array}$ \\
\hline Water (Control) & $6.0 \pm 0.4$ & $0.793 \pm 0.061$ & $\mathrm{ND}^{1}$ & $0.821 \pm 0.078$ \\
\hline $0.02 \mathrm{~N} \mathrm{NaOH}$ & $13.0 \pm 1.0$ & $0.079 \pm 0.005$ & $0.158 \pm 0.014$ & $0.872 \pm 0.081$ \\
\hline $0.02 \mathrm{~N} \mathrm{CH}_{3} \mathrm{COOH}$ & $3.0 \pm 0.2$ & $0.039 \pm 0.003$ & $0.178 \pm 0.021$ & $1.150 \pm 0.161$ \\
\hline $0.02 \mathrm{~N} \mathrm{HCl}$ & $1.5 \pm 0.1$ & $0.118 \pm 0.021$ & $0.079 \pm 0.006$ & $1.189 \pm 0.125$ \\
\hline
\end{tabular}

${ }^{1}$ Not detected 
(a)

H. sapiens HSP70
C. elegans HSP70

(b)

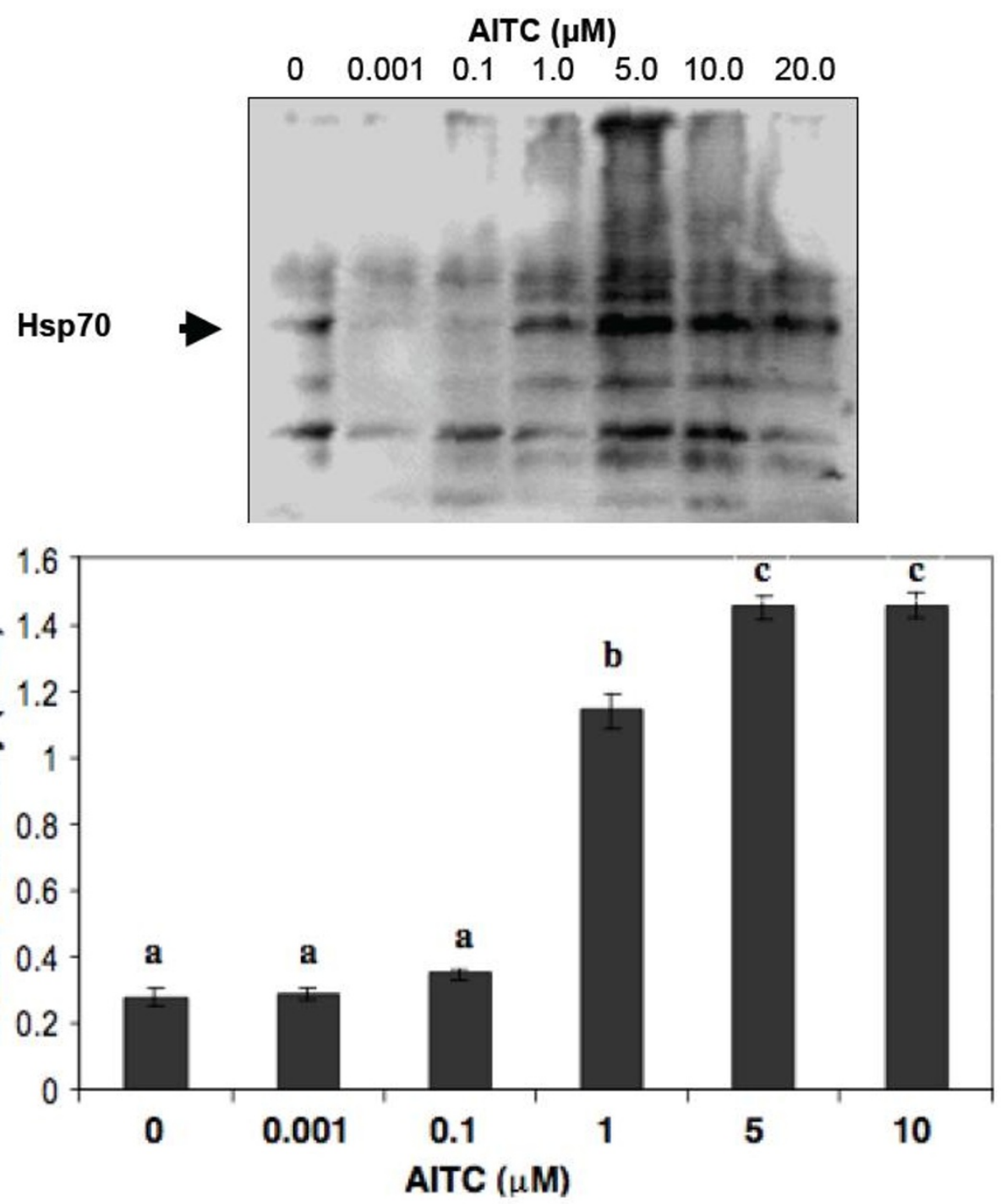

(c)

Figure 2 AITC induces expression of HSP70 in C. elegans when treated with 0-10 $\mu$ M AITC for 2 h at room temperature. (a) Human HSP70 (Accession No. NM_005346), residues 429-480, show 98\% homology with C. elegans HSP70A (Accession No. M18540). A monoclonal antibody directed against a synthetic peptide for this region of the human protein was obtained to detect the C. elegans homologue (b) Increasing concentrations of AITC induce greater expression of HSP70, indicated with arrowhead. Proteins in cell lysates from AITC treated C. elegans cultures were separated by SDS-PAGE and HSP70 protein detected using the anti-HSP70 monoclonal antibody. (c) Increasing concentrations of AITC induce HSP70A mRNA expression in C. elegans, as determined by qRT-PCR. Bars on the columns represent standard deviations of three values. Data was analyzed by one-way ANOVA. Values marked with different letters were significantly $(p<0.01)$.

bioassays of its toxicity are required for the development of these products. The present work could help the mustard industry develop the burgeoning biopesticide market.

The current industrial AITC assay method requires a two-hour incubation at $37^{\circ} \mathrm{C}$ prior to steam distillation and titration. In our hands, five minutes incubation time at room temperature and near-neutral $\mathrm{pH}$ were sufficient to hydrolyze much of the glucosinolate to AITC. Therefore, samples with normal myrosinase activity will quickly release AITC from sinigrin. However, even a greatly degraded myrosinase activity could release all of 
Table 2 Effect of B.juncea cv. Arrid on AlTC toxicity

\begin{tabular}{ccc}
\hline AITC $(\mu \mathrm{M})$ & Ground Seed $(\boldsymbol{\mu g})$ & HSP70 $(\mathbf{n g} / \mathbf{m g})^{\mathbf{1}}$ \\
\hline 0.0 & 0.0 & $0.0 \pm 0.0^{\mathrm{a}}$ \\
0.001 & - & $74.0 \pm 4.1^{\mathrm{b}}$ \\
- & 0.01445 & $0.0 \pm 0.0^{\mathrm{a}}$ \\
0.001 & 0.01445 & $2.1 \pm 4.0^{\mathrm{a}}$ \\
0.1 & - & $75.2 \pm 5.4^{\mathrm{b}}$ \\
- & 1.445 & $0.0 \pm 0.0^{\mathrm{a}}$ \\
0.1 & 1.445 & $8.1 \pm 4.2^{\mathrm{c}}$ \\
1.0 & - & $98.1 \pm 4.8^{\mathrm{d}}$ \\
- & 14.45 & $0.0 \pm 0.0^{\mathrm{a}}$ \\
1.0 & 14.45 & $17.0 \pm 4.1^{\mathrm{e}}$ \\
5.0 & - & $80.0 \pm 6.1^{\mathrm{d}}$ \\
- & 72.25 & $0.0 \pm 0.0^{\mathrm{a}}$ \\
5.0 & 72.25 & $54.5 \pm 5.1^{\mathrm{f}}$ \\
10 & - & $79.1 \pm 5.5^{\mathrm{d}}$ \\
- & 144.5 & $30.2 \pm 4.2^{\mathrm{g}}$ \\
10.0 & 144.5 & $76.2 \pm 5.1^{\mathrm{d}}$ \\
\hline
\end{tabular}

${ }^{1} \mathrm{C}$. elegans cultures were exposed to AITC $(0-10 \mu \mathrm{M}), B$. juncea $\mathrm{cv}$. Arrid (0$144.5 \mu \mathrm{g})$ or AITC $(0-10 \mu \mathrm{M})+B$. juncea $\mathrm{cv}$. Arrid $(0-144.5 \mu \mathrm{g})$ for $2 \mathrm{~h}$ at room temperature and the total protein extract was analyzed by ELISA for the presence of HSP70 protein.

Data was analyzed by two-way ANOVA $(n=4)$.

Values marked with different letters were significantly different from each other $(p<0.01)$.

the AITC from endogenous sinigrin in ground seed in a two-hour period. The spice trade assay is designed to determine the total release of AITC from mustard but samples with diminished enzyme activity may not be detected by this method. Shorter duration of incubation is necessary to determine variations in the rate of AITC release among samples.

Attempts also were made to inhibit or reduce AITC release by manipulating the $\mathrm{pH}$ of the extraction medium. The results indicated that myrosinase required a $\mathrm{pH}$ of 6.0 for optimum activity, and that a change in $\mathrm{pH}$ did not impact the substrate but altered the release of AITC. While it is known that acidic conditions may hydrolyze glucosinolates to produce nitriles and other products [18], the conditions employed in many of these conversions included a high temperature $\left(100^{\circ} \mathrm{C}\right)$. Therefore, our observation that the substrate concentration was not impacted during a brief treatment of the meal with acid followed by neutralization is not unexpected. Eylen et al. [19] studied the thermal and pressure stability of myrosinase at temperatures of $60-75^{\circ} \mathrm{C}$ and pressures from ambient to $1000 \mathrm{MPa}$. Myrosinase was found to be stable at $600 \mathrm{MPa}$ pressure at temperatures up to $60^{\circ} \mathrm{C}$. At low pressures, there was an antagonistic effect between temperature and pressure. They suggested that the high-pressure stability of myrosinase may present a valuable alternative to thermal treatment if one wants to retain myrosinase activity. The conditions for inactivation of myrosinase using microwave energy also were studied with a response surface design. Microwave irradiation at $2450 \mathrm{MHz}$ for $2.5 \mathrm{~min}$ inhibited myrosinase and decomposed glucosinolates [20].

In the present investigation, C. elegans was used to study AITC-mediated stress or toxicity by investigating expression of HSP70. RT-qPCR revealed dosedependent expression of HSP70 in C. elegans due to exposure to AITC. As there may be more than a single mode of action for glucosinolate toxicity, and toxicity may be due to other compounds present in ground mustard seed, a sensitive ELISA method was developed to detect HSP70 in C. elegans treated with AITC and/or ground seed. Together, these results indicate that 1) ground mustard seed toxicity is likely due to AITC, and 2) ground mustard seed acts as an AITC antagonist or absorbent, reducing its toxicity in C. elegans. These findings suggest that HSP70 could be used as a universal tool for studying mustard toxicity.

If AITC and mustard are to be used more widely in new pesticide products, questions will arise regarding both the risks to non-target organisms and the efficacy of the compound on target organisms. The regulatory environment will often require extensive testing for compounds in the environment, yet the presence of a compound does not imply either impact or toxicity. The need for expensive analytical tests may slow the introduction of new products with potent toxicity. Conversely, simple and robust tests may aid in the development of suitable policy and regulations regarding the deployment of the compound or material. The HSP approach of using a sentinel organism could be a useful tool to allow the determination of toxicity in situ and to potentially enable the deployment of mustard as a biopesticide.

\section{Abbreviations}

AITC: allyl isothiocyanate; qRT-PCR: quantitative reverse transcription polymerase chain reaction; ELISA: enzyme-linked immunosorbant assay

\section{Acknowledgements}

The authors are thankful to the Agriculture Development Fund, Government of Saskatchewan for financial support for this research. Ms. Saini is also thankful to the University of Saskatchewan for providing the Devolved Scholarship, the Blake John Memorial Scholarship, the Rene Vandeveld Bursary, Travel Award and Education Enhancement Award. We thank Dr. L Young for editing and preparation of the manuscript for submission.

\section{Author details}

${ }^{1} 51$ Campus Drive, Department of Food and Bioproduct Sciences, University of Saskatchewan, Saskatoon, Saskatchewan S7N 5A8, Canada. ${ }^{2} 343-111$ Research Drive, Helix BioPharma Corp, Saskatoon, Saskatchewan S7N 3R2, Canada. ${ }^{3} 51$ Campus Drive, Department of Plant Sciences, University of Saskatchewan, Saskatoon, Saskatchewan S7N 5A8, Canada.

\section{Authors' contributions}

Ms. S designed and performed the experiments presented in this manuscript. Ms. S also wrote the initial draft of the manuscript. All three authors were involved with the analysis and interpretation of the data. 


\section{Competing interests}

Dr. Reaney has been awarded patent number WO 2009/079792. Portions of this work were included in Ms. Saini's MSc thesis.

Received: 5 December 2010 Accepted: 17 November 2011

Published: 17 November 2011

\section{References}

1. Bones AM, Rossiter JT: The myrosinase-glucosinolate system, its organization and biochemistry. Physiol Plant 1996, 97:194-208.

2. Fahey JW, Zalcmann AT, Talalay P: The chemical diversity and distribution of glucosinolates and isothiocyanates among plants. Phytochem 2001, 56:5-51.

3. Fenwick GR, Heaney RK: Glucosinolates and their breakdown products in cruciferous crops, foods and feeding stuffs. Food Chem 1983, 11:249-271.

4. Mithen R: Glucosinolates-biochemistry, genetics and biological activity. Plant Growth Reg 2001, 34:91-103.

5. Noble RRP, Harvey SG, Sams CE: Toxicity of Indian mustard and allyl isothiocyanate to masked chafer beetle larvae. Plant Health Prog 2002.

6. Smolinska U, Morra MJ, Knudsen GR, James RL: Isothiocyanates produced by Brassicaceae species as inhibitors of Fusarium oxysporum. Plant Dis 2003, 87:407-412.

7. Tsao R, Peterson CJ, Coats JR: Glucosinolate breakdown products as insect fumigants and their effect on carbon dioxide emission of insects. BMC Ecology 2002, 2:5.

8. Mayton HS, Olivier C, Vaughn SF, Loria R: Correlation of fungicidal activity of Brassica species with allyl isothiocyanate production in macerated leaf tissues. Phytopath 1996, 86:267-271.

9. Winther M, Nielsen PV: Active packaging of cheese with allyl isothiocynate, an alternative to modified atmosphere packaging. I Food Protect 2006, 69:2430-2435.

10. Tunc SE, Chollet E, Chalier P, Preziosi-Belloy L, Gontard N: Combined effect of volatile antimicrobial agents on the growth of Penicillium notatum. Int J Food Microbiol 2007, 113:263-270.

11. Potter MJ, Davies K, Rathjen AJ: Suppressive impact of glucosinolates in Brassica vegetative tissues on root lesion nematode Pratylenchus neglectus. J Chem Ecol 1997, 24:67-80.

12. Buskov S, Serra B, Rosa E, Sorenses H, Sorensen JC: Effects of intact glucosinolates and products produced from glucosinolates in myrosinase-catalyzed hydrolysis on the potato cyst nematode (Globodera rostochiensis Cv. Woll). J Agric Food Chem 2002, 50:690-695.

13. Vierling E: The roles of heat shock proteins in plants. Ann Rev Plant Physiol Plant Mol Biol 1991, 42:579-620.

14. Parsell DA, Lindquist AS: Heat shock proteins and stress responses. In The Biology of heat shock proteins and molecular chaperones. Edited by: Morimoto Rl, Tissieres A, Georgopoulos C. New York: Cold Spring Harbor Laboratory Press; 1994:457-494.

15. Suri SS, Dhindsa RS: A heat-activated MAP kinase (HAMK) as a mediator of heat shock response in tobacco cells. Plant Cell Environ 2008, 31:218-226.

16. Heschl MF, Baillie DL: Characterization of the hsp70 multigene family of Caenorhabditis elegans. DNA 1998, 8:233-243.

17. Raquet D: Estimation of essential oil in mustard. Ann Chim Anal 1912, 17:174-178.

18. Kirk LD, Mustakas GC, Griffin EL, Booth AN: Crambe seed processing: decomposition of glucosinolates (thioglucosides) with chemical additives. J Am Oil Chem Soc 1971, 48:845-850.

19. Eylen DV, Hendrickx IM, Loey AV: Temperature and pressure stability of mustard seed (Sinapis alba L.) myrosinase. Food Chem 2006, 97:263-271.

20. Verker R, Dekker M: Glucosinolates and myrosinase activity in red cabbage (Brassica oleracea L. Var. Capitita f. rubra DC.) after various microwave treatments. J Agric Food Chem 2004, 52:7318-7323.

\section{Submit your next manuscript to BioMed Central and take full advantage of:}

- Convenient online submission

- Thorough peer review

- No space constraints or color figure charges

- Immediate publication on acceptance

- Inclusion in PubMed, CAS, Scopus and Google Scholar

- Research which is freely available for redistribution 